\title{
Seroprevalence and associated risk factors of canine Leishmania infantum infection in selected towns of Southwest and West Shewa Zones of Oromia, Ethiopia
}

Endrias Zewdu Gebremedhin ( $\nabla$ endrias.zewdu@gmail.com )

Ambo University

Weraka Weya

Ambo University

Chala Dima

National Animal Health diagnostic Investigation center, sebeta, Ethiopia

Demeke Zewde

National Animal Health Diagnostic investigation center, Sebeta, Ethiopia

Vincenzo Di Marco Lo Presti

Istituto Zooprofilattico Sperimentale della Sicilia Adelmo Mirri

Maria Vitale

Laboratory of genetics of microorganisms, Italy

\section{Research Article}

Keywords: Dogs, Ethiopia, Leishmania infantum, Risk factors, Seroprevalence, Zoonosis

Posted Date: January 6th, 2022

DOI: https://doi.org/10.21203/rs.3.rs-1227368/v1

License: (c) (i) This work is licensed under a Creative Commons Attribution 4.0 International License.

Read Full License 


\section{Abstract \\ Background}

Canine Leishmania infantum infection is a major vector-borne zoonosis. Most cases of canine leishmanias are caused by Leishmania infantum, but other species can also be found. In the Old and New Worlds, leishmaniasis is spread by the bite of phlebotomine female sandflies of the genera Phlebotomus and Lutzomyia respectively. The objectives of the study were to estimate the seroprevalence and associated risk factors in Weliso, Ambo, and Ejaji towns of South-West and West Shewa Zones, Oromia, Ethiopia.

\section{Methods}

A cross-sectional study was conducted from October 2019 to September 2020. The study population consists of dogs found in the study towns. The study subjects include 368 dogs selected by using a simple random sampling method. A blood sample $(5 \mathrm{ml})$ was collected to test for the presence of rK39 antigen inducing specific antibodies using an Indirect ELISA kit. All the data were analyzed using the STATA version 14 software program. Pearson's Chi-square and logistic regression tests were used to evaluate the association between the seropositivity of canine Leishmania infantums and hypothesized risk factors.

\section{Results}

An overall canine Leishmania infantum seroprevalence of $84.24 \%$ (95\% confidence interval [CI]: 80 - 88\%) was obtained. In Weliso, Ambo, and Ejaji towns canine Leishmania infantum seroprevalence of $79.82 \%$ (95\% Cl: 71-87\%), 76.11\% (95\% Cl: 67-84\%), and 93.84\% (95\% Cl:89 - 97\%) were found respectively. Univariable logistic regression analysis showed that town $(P=0.001)$, season $(P=0.001)$, mixed living environment $(P=0.003)$, and Kebele $(P<0.05)$ were significantly associated with Leishmania infantum seropositivity. However, the multivariable analysis indicated that wet season $(P=0.001)$ and a mixed living environment $(P=0.025)$ were independent predictors of canine Leishmania infantum seropositivity.

\section{Conclusion}

The seroprevalence of canine Leishmania infantum in dogs was very high. Wet season and mixed living environment are predictors of seropositivity. The high percentage of seropositive dogs indicates the potential role of dogs to maintain the infection and the possible spread of L. infantum infection to humans. Therefore, improvement of the living environment and health care facilities of domesticated dogs, community awareness and health education, and further epidemiological studies are suggested. 


\section{Background}

Canine Leishmania infantum (CLI) infection is a major vector-borne zoonosis. Most cases of canine leishmaniasis are caused by L.infantum, but other species can also be found [1]. Leishmania infantum is obligate Intramacrophage protozoa of the genus Leishmania in the family Trypanosomatidae [2]. The parasite is of great public health and veterinary significance. Leishmaniasis is a neglected tropical disease (NTD) that is transmitted by the bite of phlebotomine female sandflies of the genera Phlebotomus and Lutzomyia in the Old and New World, respectively. About 53 species of the parasite have been described from different regions of the world; Of these, 31 species are known to be parasites of mammals and 20 species are pathogenic to human beings $[3,4]$.

Canine Leishmania infantum causes an important disease that occurs on all continents except Oceania [5]. Leishmaniasis is endemic in 98 countries and 350 million people are at risk of contracting the disease. Leishmaniases are a group of diseases with a wide range of clinical manifestations. There are three forms of leishmaniases, visceral (VL), cutaneous (CL), and mucocutaneous leishmaniasis (MCL). Of the three forms, $\mathrm{VL}$ is highly fatal and the most prevalent form in eastern Africa, followed by $\mathrm{CL}$ and MCL [6].

There is an estimated incidence of 1 to 1.5 million cases of $C L$ or MCL (mainly occurring in Brazil, Peru, and the Plurinational State of Bolivia) and 500,000 cases of VL primarily in South America, East Africa, and the Indian Subcontinent. More than $90 \%$ of the world's VL cases occur in Bangladesh, Brazil, Ethiopia, India, Nepal, and Sudan. Eastern Africa has the second-highest number of VL cases, after the Indian Subcontinent, and the disease is endemic in parts of Eritrea, Ethiopia, Kenya, Somalia, North Sudan, Southern Sudan, and Uganda [6, 7].

Ethiopia is one of the ten countries with the highest estimated case counts, which together account for 70 to $75 \%$ of global estimated VL incidence. Of the estimated 2 million cases, only around 600,000 are reported [8]. The epidemiology of VL has changed in Ethiopia, with endemic areas spreading continuously [9]. This is in line with the existing trend of climate change, rapid urbanization, and massive population movements affecting the range and population density of the insect vectors and reservoir hosts of the disease, resulting in a cumulative elevation in the rate of human exposure to the infection [10].

Leishmaniasis infects numerous species of mammals, including humans. Among domestic animals, dogs are the most important species in the epidemiology of the disease. Dogs play an important role in the ecology and control of zoonotic visceral leishmaniasis (ZVL) as they are the predominant domestic reservoir for the disease, with greater than $10 \%$ seropositivity often evident in dogs before the emergent of VL that has been observed in humans [11]. Hence, dog ownership is a major risk factor of VL in multiple endemic countries [12]. The digenetic life-cycle of the Leishmania parasite involves the delivery of flagellated promastigotes to mammalian hosts during a sandfly bite, where non-flagellated amastigotes develop within phagocytic mononuclear cells. These cells are taken up by the phlebotomine sandfly during feeding and then develop into flagellated promastigotes, completing the lifecycle [13]. 
Apart from a general species-specific organtropism of Leishmania infantum, intra-specie intrinsic characteristics are also a relevant factor to consider. Dermo-tropic and viscera-tropic L. infantum strains modulate the sandflies biting time on the host leading to the delivery respectively, of a high or low dose of meta-cyclic promastigotes into the skin which will impact the parasite tropism and manifestation of the disease [14]. Even strains belonging to the same zymodeme have been associated with differential infectivity [15].

The objectives of the current study were to estimate the seroprevalence and associated risk factors of CLI in Weliso, Ambo, and Ejaji towns of South-West and West ShewaZones, Oromia, Ethiopia.

\section{Methods}

The study was carried out in the towns of Weliso in the South-West Shewa Zone, and Ambo and Ejaji in theWest Shewa Zone, Oromia, Ethiopia (Figure 1). Weliso district is one of the 14 districts found in the South-West Shewa Zone. Weliso town is an administrative town of Weliso district, and the South-West Shewa Zone, which is located $114 \mathrm{~km}$ southwest of Addis Ababa and the district has a longitude of $37^{\circ}$ 57' 59.99" E and latitude of $8^{\circ} 31^{\prime}$ 59.99" $\mathrm{N}$ with an elevation of 2063 meters above sea level (m.a.s.l). The annual rainfall and a temperature range from $950-2,718.3 \mathrm{~mm}$ and $13.6^{\circ} \mathrm{C}-25^{\circ} \mathrm{C}$ respectively.

Ambo town is an administrative town of Ambo district, and the West Shewa Zone, which is located 115 $\mathrm{km}$ West of Addis Ababa and the town has a latitude of $8^{\circ} 59^{\prime} \mathrm{N}$ and longitude of $37^{\circ} 51^{\prime} \mathrm{E}$ and an elevation of $2101 \mathrm{~m}$.a.s.l. The annual rainfall and a temperature range from $800-1000 \mathrm{~mm}$ and $15^{\circ} \mathrm{C}-29^{\circ} \mathrm{C}$ respectively. The mean temperature is $18.6^{\circ} \mathrm{C}$. Whereas, Ejaji town is the administrative town of Elu Gelan district, which is located $90 \mathrm{~km}$ West of the zonal capital, Ambo, and $215 \mathrm{~km}$ West of Addis Ababa. Ejaji town has a longitude of $37^{\circ} 9.8^{\prime} \mathrm{E}$ and a latitude of $8^{\circ} 59.9^{\prime} \mathrm{N}$ and has an altitude ranging from $1565-1790$ m.a.s.l. The annual rainfall and a temperature range from $2000-2300 \mathrm{~mm}$ and $27^{\circ} \mathrm{C}$ and $30^{\circ} \mathrm{C}$ respectively.

The climatic conditions of the study areas vary from very hot (lowland) to mid-temperate (midland) and cold temperatures (highland).

\section{The study population and study animals}

The study population consists of dogs found in the study towns. Local, cross, and exotic breeds of dogs are found in the study towns. Nevertheless, local breeds are predominantly found in the study areas, followed by a cross and exotic breeds of dogs. Dogs are kept for house guard in most parts of urban areas in the country; however, in rural areas they are also used for protecting livestock from thieves in the evening and hunting. In this study, healthy dogs above six months of age, both sexes, and different kinds of breeds were included. A total population of 7,098 dogs is found in the current study towns. Of these, the highest population of dogs is found in Ejaji $(2,816)$, followed by Ambo $(2,180)$, and Weliso $(2,102)$ towns. Dogs aged 6 months; 6 months to 1.5 years, 1.6 to 7 years, and above 7 years were considered as juvenile, adolescent, adult, and geriatrics respectively [16]. 


\section{Study design and sampling methods}

This cross-sectional study was carried out from October 2019 to September 2020. Dogs were brought to the selected places in the study areas arranged for sample collection. Dog owners were invited to the area through microphone announcement with the help of the kebele (the smallest formal administrative unit in a town) administration members. The study animals were selected by using a simple random sampling method. This consists of randomly drawing " $n$ " individuals from " $N$ " people in a sampling frame list. Dog owners were informed to handle their dogs properly up to the end of the sample collection process. Dogs that cannot get to the selected locations were sampled in their homes.

\section{Inclusion and exclusion criteria}

Agreement by the dog owner to participate in the study was an inclusion factor. Accessible dogs whose owners are willing for sampling and dogs above six months of age were included in the study while highly debilitated, sick dogs and those under treatment were excluded. Dogs known for their extreme aggressiveness were also excluded from the study.

\section{Sample size determination}

The desired sample size for the study was calculated by the formula given by Thrusfield[17] assuming $50 \%$ expected seroprevalence of $\mathrm{CLI}$ in the study areas (since there was no previous study in the current study areas) and a $5 \%$ level of precision. The sample size (n) is determined by the formula:

$$
\mathrm{n}=\frac{1.96^{2} \times P_{\exp }\left(1-P_{\exp }\right)}{d^{2}}
$$

Where, $\mathrm{n}$ sample size required, $1.96=$ the value of $\mathrm{Z}$ at $95 \%$ confidence interval, $\mathrm{P}_{\exp }=$ expected seroprevalence, $\mathrm{d}=$ desired absolute precision

$$
\mathrm{n}=\frac{1.96^{2} \times 0.5(1-0.5)}{0.05^{2}}=384 \mathrm{dogs}
$$

Although, the calculated sample size was 384, due to kit shortage 368 dogs were tested (i.e., 146, 113, and 109 dogs from Ejaji, Ambo, and Weliso towns respectively).

\section{Sampling procedure and techniques}

Before blood collection, personal protective pieces of equipment like disposable gloves, gowns, and waste management materials were made ready and used properly. The dogs were restrained in portable dog crush, by rope, and dog catcher accordingly. Then, the site of blood collection (cephalic and lateral saphenous vein) was washed with soap and water, shaved with a sterile surgical blade, disinfected with 
$70 \%$ isopropyl alcohol, and tied by the tourniquet. A blood sample $(5 \mathrm{ml})$ was collected from each dog by intravenous cannulation with plain vacutainer tubes and needles.

Each tube was individually identified and the blood was allowed to clot and then centrifuged at 3000 revolutions per minute (rpm) for 5-10 min to obtain serum. Centrifugation took place in the field, i.e., during the evening in the town of each study area., The serum samples were then immediately transported using an icebox containing ice packs to the Ambo University Zoonosis and Food Safety Laboratory and stored at $-20^{\circ} \mathrm{C}$ until serologically tested. Finally, the serum samples were transported using an icebox to Sebeta National Animal Health Diagnostic and Investigation Center (NAHDIC) for Indirect ELISA Serological examination.

\section{I-ELISA}

All the collected serum samples were tested for the presence of rK39 antibodies against CLI following the protocol of the manufacturer of the indirect ELISA kit (IDvet Innovative Diagnostics, ID Screen®, Leishmania Indirect, France).

\section{Data management and analysis}

The raw field data obtained from sampled dogs and findings of laboratory examination were entered into Microsoft Excel 2019 Spreadsheet to create a database followed by refining and coding. The collected data were analyzed using the STATA version 14 software program (Stata Crop. College Station, USA). Descriptive statistics were used to summarize the data. Pearson's Chi-square ( ) and logistic regression (univariable and multivariable) tests were used to evaluate the association between hypothesized potential risk factors like town, season, kebele, sex, age, breed, living environment, and presence of other domesticated animals in the households with CLI seropositivity. Additionally, the collinearity (confounding) of the risk factors was also analyzed and from collinear risk factors, only one independent variable with a strong biological association with the disease outcome was selected and used for the final logistic regression model. Those variables with $P \leq 0.25$ in the univariable logistic regression analysis were further analyzed using multivariable logistic regression after checking for multicollinearity. In all the cases $P<0.05$ was set for significance.

\section{Ethical statement}

The study protocols were approved by the ethical review committee of the Ambo University, Mamo Mezemir Campus, School of Veterinary Medicine. Each study subject involved in the study gave oral consent to participate and only those individuals who showed their willingness were selected to participate in the study. All dogs were enrolled in this study with informed permission from their caretakers, and all dogs sampled were examined with the assistance and acceptance of their owners. Blood samples were collected by the researcher according to the good practices of veterinary medicine 
i.e., all animals were handled strictly by following the good animal handling practice to minimize animal sufferings during sampling.

\section{Results}

Frequency distribution analysis of potential risk factors

From the overall 368 dogs studied, the majority are from Ejaji (146/368, 39.67\%), followed by Ambo $(113 / 368,30.71 \%)$, and Weliso $(109 / 368,29.62 \%)$ towns (Table 1$)$.

Seroprevalence

The current study estimated an overall Canine L. infantum seroprevalence of $84.24 \%$ (95\% Cl: $80-88 \%$ ). In Weliso, Ambo, and Ejaji towns Canine L. infantum seroprevalence of 79.82\% (95\% Cl: 71 - 87\%), 76.11\% (95\% Cl: 67 - 84\%), and 93.84\% (95\% Cl: 89 - 97\%) was found respectively. The seroprevalence was significantly high $(P<0.05)$ in dogs of Ejaji town $(93.84 \%)$ compared to Ambo $(76.11 \%)$ [Table 2].

\section{Risk factors}

All independent variables considered in this study were non-collinear with each other except town and season ( $r=0.6312)$, kebele and season $(r=0.5338)$, and kebele and town $(r=0.5782)$. Among collinear independent variables season was selected for the final multivariable model. Furthermore, those independent variables with univariable $P 0.25$ such as season, breed, and living environment were selected for the multivariable logistic regression analysis. CLI seropositivity was significantly associated with a wet season $(P=0.001)$ and a mixed living environment $(P=0.025)$. The likelihood of CLI seropositivity of dogs was 2.91 times higher in the wet than the dry season. The likelihood of CLI seropositivity of dogs was also 2.19 times higher in dogs living in a mixed environment (indoor and outdoor) as compared to indoor living dogs (Table 2).

\section{Discussion}

\section{Seroprevalence}

The current study revealed an overall high canine L. infantum seroprevalence (310/368, 84.24\%). Of this, the highest seroprevalence was observed in Ejaji town (137/146, 93.84\%) followed by Weliso (87/109, $79.82 \%)$, and Ambo (86/109, 76.11\%). The current study findings were significantly higher than the canine leishmaniasis seroprevalences of $13.9 \%$ reported in BenishangulGumuz Regional State, Ethiopia [18], 40\% in dogs in North-West Ethiopia [19], 6.9\% in domesticated dogs in Eastern Sudan [20], 11.7\% in stray dogs, $9.7 \%$ in National Guard dogs, and $5.9 \%$ in farm dogs in Algeria [21].

Much lower Seroprevalences CLI than the present study have also been reported previously such as $6.5 \%$ in an endemic focus of Satlujiver valley of Himachal Pradesh (India) [22], 35\% VL among dogs in VL endemic areas of Mymensingh district, Bangladesh [23], 26\% L. infantum infection in dogs in Spain [24], $6.31 \%$ in Portugal [25],4.9 to $12.6 \%$ in a public kennel in Bologna, Italy [26],5.2\% (L'Aquila, Abruzzo region) 
to $21.8 \%$ (Campobasso, Molise region) in Italy [27], 22\% in Brazil [28], 22\% in Colombia [29], and $12 \%$ in the central region of Colombia [30].

The variation in seroprevalence between the current study and the aforementioned reports might be possibly due to variations in geographical location, i.e., geographical regions with various weathers have shown different seroprevalence of L.infantum in dogs. Since the seroprevalence of CLI and HVL is associated with weather conditions and humidity in endemic areas [31]. It could also possibly be due to the variation in the suitability of the environment, activities of sandflies, and the country's prevention and control strategies against CLI in predominant reservoir host, and vectors of leishmaniasis. Noticeably, the prevalence of canine leishmaniasis also varies between different regions depending on the serological tests used in the diagnosis [30].

\section{Risk factors}

The current study revealed that wet season $(P=0.001)$ and mixed living environment $(P=0.025)$ were significantly associated with CLI seropositivity possibly owing to the different activities of sandflies in these regions favored by suitable environmental conditions for its breeding and more exposure of dogs to sandfly bites. The lower infection in household dogs is possibly due to the lower chance of exposure to sandfly bites [32].

A relatively high percentage of infected dogs having outdoor access as compared to owned dogs without outdoor access might suggest dogs that have outdoor access might be the potential source for human infection. Free-roaming is an important factor for achieving infection [33]. The likelihood of CLI seropositivity of dogs in the wet season (AOR=2.91) and mixed living environment (AOR=2.19) was significantly higher compared to the dry season and indoor living environment respectively.

The current study findings were in close agreement with the studies conducted in Himachal Pradesh, India; where domestic, as well as stray dogs, suggesting that they are perhaps harboring the L. donovani-infantum and providing a constant reservoir for the infection [22], in Mymensingdistrict, Bangladesh; where the living status of the dogs (street or owned)was a potential risk factor [23], and in Italy, where being a dog hosted in a kennel, seems not to be a factor increasing the probability that dogs show seropositivity, even in long-term sheltering conditions [27].

However, the current findings disagree with the studies conducted in Algeria; where the infection was significantly more prevalent in older dogs than younger ones, in stray dogs than owned dogs, and rural dogs than urban ones [21], in Brazil, where the re-emergence of the disease appears to be a consequence of the discontinuation of control programs[28], and in the central region of Colombia, where owned dogs were strongly associated with canine leishmaniasis [30].

\section{Limitations of the research}


This study is believed to have certain constraints. Mainly, it is a financial and diagnostic kit shortage. From the calculated sample size $(n=384)$, only 368 dogs were tested due to diagnostic kit shortage. The findings of this study should be cautiously interpreted for all dog populations in the study areas. In the absence of stray dog ownership, the current study was limited to only those dogs that have an owner, and also rural dog populations were not included in the study. This can often create challenges to generalize the findings of the current research to the whole dog population in the area. Canine L. infantum is largely uninvestigated and neglected in Ethiopia. Inadequate information is available about CLI in Ethiopia in general and absent in the selected study areas in particular. Hence, it was difficult to gain enough information and to discuss the results obtained with other studies conducted in similar study areas. Therefore, the current study results were discussed with many reports from abroad.

\section{Conclusions}

In the current study, a very high percentage of an overall CLI seroprevalence (84.21\%) in dogs was reported. Wet season and mixed living environment of dogs were predictors of CLI seropositivity. The high percentage of seropositive dogs indicates the potential role to maintain the infection and possible spread of L. infantum infection to humans. Therefore, improvement of living environment and health care facilities of domesticated dogs, community awareness and health education, and further epidemiological studies are suggested.

\section{Declarations}

\section{Acknowledgments}

The authors are very much thankful to Ambo University Research and Community Engagement Vice President Office and the Italian National Reference Centre for Toxoplasmosis at the Istituto Zooprofilattico Sperimentaledella Sicilia A. Mirri, Italy for their financial support. We are also grateful to Mamo Mezemir Campus School of Veterinary Medicine and Department of Veterinary Science for the facilitation of the research, and the National Animal Health Diagnostic and Investigation Center for their vigorous support throughout this research work.

\section{Ethics approval and consent to participate}

This research project was approved by the ethical committee for animal experimentation of Ambo University, Ethiopia (Ref. No. RD/AREC/004/2016). All animals were handled strictly following the good animal handling practice to minimize animal sufferings during sampling. Informed verbal consent was obtained from the dog owners.

\section{Consent for publication}

Not applicable. 
Availability of data and materials

The data supporting the conclusions of this article are included within the article and anonymized data could be shared upon request to the corresponding author.

\section{Competing interest}

The authors declare that they have no competing interests.

\section{Funding}

This work was supported by Ambo University and the Italian National Reference Centre for Toxoplasmosis at the IstitutoZooprofilatticoSperimentaledella Sicilia A. Mirri, Italy (grant No. RF 2007/RC).

\section{Authors' contributions}

WW Participated in proposal preparation, collection of data, analysis of data, and manuscript drafting. EZ conceived the research idea, participated in proposal preparation, supervising, data analysis and interpretation, manuscript reviewing, and commenting. CD and DZ did an Indirect ELISA serological test and reviewed the manuscript. VMLP and MV participated in the design, drafting, and critical review of the manuscript. All Authors read and approved the final manuscript.

\section{Author details}

${ }^{1}$ Ambo University, MamoMezemir Campus, School of Veterinary Medicine, Department of Veterinary Sciences, P.O.Box 19, Ambo, Ethiopia

${ }^{2}$ National Animal Health Diagnostic and Investigation Center, P. O. Box 04, Sebeta, Ethiopia.

${ }^{3}$ Istituto Zooprofilatticosperimentaledella Sicilia “A. Mirri”, Area Territoriale, BarcellonaPozzo di Gotto, Italy.

${ }^{4}$ Laboratory of Genetics of Microorganisms, IstitutoZooprofilatticoSperimentale of Sicily, Via Gino Marinuzzi 3, 90129 Palermo, Italy.

\section{Abbreviations}

AOR: adjusted odds ratio; Cl: confidence interval; $\mathrm{CL}$ : cutaneous leishmaniasis; CLI: canine Leishmania infantum; COR: crude odds ratio; ELISA: enzyme-linked immunosorbent assay; HVL: human visceral leishmaniasis; M.A.S.L.: meter above sea level; MCL: mucocutaneous leishmaniasis; NTD: neglected tropical disease; NAHDIC: national animal health diagnostic and investigation center; POS: positive; RPM: revolution per minute; VL: visceral leishmaniasis; ZVL: zoonotic visceral leishmaniasis. 


\section{References}

1. Ashford RW. The leishmaniases as emerging and reemerging zoonoses. Int J Parasitol.2000; 30: 1269-81.

2. Azevedo E, Oliveira L, Lima KC, Terra R, Dutra ML, and Salerno VP. Interactions between Leishmania braziliensis and macrophages are dependent on the cytoskeleton and myosin. J.Parasitol. 2012; 10: 1155-2012.

3. Alemayehu B, Alemayehu M. Leishmaniasis: A Review on Parasite, Vector and Reservoir Host. Health Sci. J. 2017; 11(4): 519.

4. Gramiccia M, Gradoni L. The current status of zoonotic leishmaniasis and approaches to disease control. Int J Parasitol.2005; 35: 1169-80.

5. Dantas-Torres F, Salano-Gallego L, Baneth G, Ribeiro VM, de-Paiva-Cavalcanti M, Otranto D. Canine leishmaniasis in the old and new world: Unveiled similarities and differences, Trends Parasitol.2012; 28: 531-8.

6. Desjeux P. Leishmaniasis: current situation and new perspectives, Comp. Immunol. Microbiol. Infect. Dis. 2004; $27:$ 305-18.

7. Chappuis F, Sundar S, Hailu A, Ghalib H, Rijal S, Rosannan W, et al. Visceral leishmaniasis: What are the needs for diagnosis, treatment, and control? Nat. Rev. Microbiol.2007; 5: 873-82.

8. Alvar J, Velez ID, Bern C, Herrero M, Desjeux P, Cano J, et al. Leishmaniasis worldwide and global estimates of its incidence. PLoS ONE. 2012; 7(5).

9. Kebede S. Visceral leishmaniasis in Bira Abo, a kebele in Addis Zemen:seroepidemiological and Leishmania skin test survey, Master's Thesis, Addis Ababa University. 2017; https://hdl.handle.net/123456789/2972.

10. Bashaye S, Nombela N, Argaw D, Mulugeta A, Herrero M, Nieto J, et al. Risk factors for visceral leishmaniasis in a new epidemic site in Amhara Region. Ethiopia. Am J Trop Med Hyg.2009; 81: 349.

11. Lima ID, Lima ALM, Mendes-Aguiar CO, Coutinho JFV, Wilson ME, Pearson RD, et al. Changing demographics of visceral leishmaniasis in North-East Brazil: Lessons for the future. PLoS Negl Trop Dis. 2018; 12(3): e0006164.

12. Bsrat A, Berhe M, Gadissa E, Taddele H, Tekle $Y$, Hagos $Y$, et al. Serological investigation of visceral Leishmania infection in humans and its associated risk factors in Welkait District, Western Tigray, Ethiopia. ParasiteEpidemiol. Control.2018; 3(1): 13-20.

13. Handman E. Leishmaniasis: current status of vaccine development. Clin Microbiol Reviews. 2001; 14:229-43, https://doi.org/10.1128/CMR.14.2.229-243.2001.

14. Maia C, Seblova V, Sadlova J, Votypka J, Volf P. Experimental transmission of Leishmania infantum by two major vectors: a comparison between a viscera-tropic and a dermo-tropic strain. PLoS Negl Trop Dis. 2011; 5(6): e1181. 
15. Baptista-Fernandes T, Marques C, Roos-Rodrigues O, Santos-Gomes GM. Intra-specific variability virulence in L. infantum zymodeme MON-1 strains. Comp. Immunol. Microbiol. Infect. Dis. 2007; $30(1): 41-53$.

16. Kiflu B, Alemayehu H, Abdurahaman M, Negash Y, Eguale T. Salmonella Serotypes and their antimicrobial susceptibility in apparently healthy dogs in Addis Ababa, Ethiopia. BMCVet Res. 2017; 13: 134.

17. Thrusfield M. Veterinary Epidemiology. Third edition, USA: Blackwell Science; 2005; pp180-185.

18. Bejano S, Shumie G, Kumar A, Asemahegn E, Damte D, Woldie S, et al. Prevalence of asymptomatic visceral leishmaniasis in human and dog, Benishangul-Gumuz regional State Western Ethiopia. Parasites Vectors. 2021; 14: 39.

19. Kenubih A, Dagnachew S, Almaw G, Abebe T, Takele Y, Hailu A, et al. A preliminary survey of domestic animal visceral leishmaniasis and risk factors in North-West Ethiopia. Trop Med Int Health. 2015; 20(2): 205-10.

20. Hassan MM, Osman OF, El-Raba`a FM, Schalling FD, Elnaiem DA. Role of the domesticated dogs as a reservoir host of Leishmania donovani in eastern Sudan. Parasites Vectors.2009; 2: 26.

21. Adel A, Saegerman C, Speybroeck N, Praet N, Victor B, De-Deken R, et al. Canine leishmaniasis in Algeria: true prevalence and diagnostic test characteristics in groups of dogs of different functional types. Vet. Parasitol. 2016; 172: 204-13.

22. Sharma NL, Mahajan VK, Negi AK, Verma GK. The rK39 immuno-chromatic dipstick testing: A study for K39 seroprevalence in dogs and human leishmaniasis patients for the possible animal reservoir of cutaneous and visceral leishmaniasis in an endemic focus of Satluj river valley of Himachal Pradesh (India). Indian J.Dermatol.Venereol.Leprol. 2009; 75: 52-5.

23. Islam A, Rahman ML, Islam S, Debnath $P$, Alam M, Hassan MM. Seroprevalence of visceral leishmaniasis among dogs in VL endemic areas of Mymensingh District, Bangladesh. JAVAR. 2017; 4(3): 241-48.

24. Solano-Gallego L, Morell P, Arboix M, Alberola J, Ferrer, L. Prevalence of L. infantum infection in dogs living in an area of canine Leishmaniasis endemicity using PCR on several tissues and serology. J Clin Microbiol. 2001; 39(2): 560-63.

25. Cortes S, Vaz Y, Neves R, Maia C, Cardoso L, Campino L. Risk factors for canine leishmaniasis in an endemic Mediterranean region. Vet. Parasitol. 2012; 189: 189-96.

26. Baldelli R, Piva S, Salvatore D, Parigi M, Melloni O, Tamba M, et al. Canine leishman-iaasis surveillance in a northern Italy kennel. Vet. Parasitol. 2011; 179: 5761.

27. De-Massis F, Ippoliti C, lannetti S, Tittarelli M, Pelini S, Giansante D, et al. Canine Leishmaniasis: Serological results in private and kennel dogs tested over six years (2009-2014) in Abruzzo and Molise Regions, Italy. Microorganisms. 2020; 8:1915.

28. Leal GG, Carneiro M, Pinheiro A, Marques LA, Ker HG, Reis AB, et al. A risk profile for Leishmania infection in dogs coming from an area of visceral leishmaniasis re-emergence. Prev. Vet Med. 2018; 150: $1-7$. 
29. Zambrano-Hernandez P, Ayala-Sotelo MS, Fuya-Oviedo P, Montenegro-Puentes CA, Aya-Vanegas NM, Aguilera-Jaramillo G, et al. Broteurbano de leishmaniasis visceral en Neiva, Colombia (Urban outbreak of visceral leishmaniasis in Neiva, Colombia - in Spanish), Reviews Saludpublica. 2015; 7: 514-27.

30. Picón Y, Almario G, Rodríguez V, Garcia NV. Seroprevalence, clinical, and pathological characteristics of canine leishmaniasis in a central region of Colombia. J Vet Res. 2020; 64: 85-94.

31. Mohebali M, Edrissian GH, Shirzadi MR, Akhoundi B, Hajjaran H, Zarei Z, et al. An observational study on the current distribution of visceral leishmaniasis in different geographical zones of Iran and implication to health policy. Travel Med Infect Dis. 2011; 9(2):67-74.

32. Moshfe A, Mohebali M, Edrissian G, Zarei Z, Akhoundi B, Kazemi B, et al. Canine visceral leishmaniasis: asymptomatic infected dogs as a source of $L$. infantum infection. Acta. Tropica.2009; 112: $101-5$.

33. Kumthekar S, Chikweto A, Chawla P, Tiwari KP, Sharma RN. Seroprevalence of Canine Leishmania infantum in owned and stray dogs from Grenada. West Indies J Anim Res. 2014; 4(1): 131-9.

\section{Tables}

Table 1: Results of the frequency distribution of the potential risk factors of CLI in the study towns 


\begin{tabular}{|c|c|c|c|}
\hline Variables & Category & Frequency & $\%$ \\
\hline \multirow[t]{3}{*}{ Towns } & Weliso & 109 & 29.62 \\
\hline & Ambo & 113 & 30.71 \\
\hline & Ejaji & 146 & 39.67 \\
\hline \multirow[t]{2}{*}{ Seasons } & Wet & 180 & 51.09 \\
\hline & Dry & 188 & 48.91 \\
\hline \multirow[t]{8}{*}{ Kebele } & Burka Gudina & 15 & 21.47 \\
\hline & Ayetu & 23 & 19.57 \\
\hline & Hora & 28 & 18.48 \\
\hline & Yahi Geda & 41 & 11.41 \\
\hline & Ejersa & 42 & 11.14 \\
\hline & Goba & 68 & 7.61 \\
\hline & Hora Ayetu & 72 & 6.25 \\
\hline & Gora & 79 & 4.08 \\
\hline \multirow[t]{2}{*}{ Sex } & Female & 59 & 83.97 \\
\hline & Male & 309 & 16.03 \\
\hline \multirow[t]{3}{*}{ Age } & Geriatrics & 40 & 73.37 \\
\hline & Juvenile and Adolescent & 58 & 15.76 \\
\hline & Adult & 270 & 10.87 \\
\hline \multirow[t]{2}{*}{ Breed } & Exotic and cross & 64 & 82.61 \\
\hline & Local & 304 & 17.39 \\
\hline
\end{tabular}

Table 1: Results of the frequency distribution of the potential risk factors of CLI in the study towns (continued). 


\begin{tabular}{llll} 
Variables & Category & Frequency & $\%$ \\
\hline Living environment & Outdoor & 60 & 63.86 \\
\hline & Indoor & 73 & 19.84 \\
\hline & Mixed & 235 & 16.3 \\
\hline Presence of other animals & No & 132 & 64.13 \\
\hline & Yes & 263 & 35.87 \\
\hline Leishmania Status & Negative & 58 & 15.76 \\
\hline & Positive & 310 & 84.24
\end{tabular}

Table 2: Logistic regression analysis results of the association between CLI seropositivity and potential risk factors. 


\begin{tabular}{|c|c|c|c|c|c|c|c|}
\hline \multirow[t]{2}{*}{ Variable } & \multirow[t]{2}{*}{ Category } & \multirow{2}{*}{$\begin{array}{l}\text { No. } \\
\text { tested }\end{array}$} & \multirow{2}{*}{$\begin{array}{l}\text { No. Pos. } \\
\text { (\%) }\end{array}$} & \multicolumn{2}{|l|}{ Univariable } & \multicolumn{2}{|c|}{ Multivariable } \\
\hline & & & & $\begin{array}{l}\text { COR }(95 \% \\
\mathrm{Cl})\end{array}$ & $\begin{array}{l}\mathrm{P} \text { - } \\
\text { value }\end{array}$ & $\begin{array}{l}\mathrm{AOR}(95 \% \\
\mathrm{Cl})\end{array}$ & $\begin{array}{l}\mathrm{P} \text { - } \\
\text { value }\end{array}$ \\
\hline \multirow[t]{3}{*}{ Town } & Ambo & 113 & $86(76.11)$ & 1 & 1 & - & - \\
\hline & Weliso & 109 & $87(79.82)$ & $\begin{array}{l}1.24(0.66- \\
2.35)\end{array}$ & 0.506 & - & - \\
\hline & Ejaji & 146 & 137(93.84) & $\begin{array}{l}4.78(2.14- \\
10.65)\end{array}$ & $0.001^{*}$ & - & - \\
\hline \multirow[t]{2}{*}{ Season } & Dry & 188 & 145(77.13) & 1 & 1 & 1 & 1 \\
\hline & Wet & 180 & 165(91.67) & $\begin{array}{l}3.26(1.74- \\
6.12)\end{array}$ & $0.001^{*}$ & $\begin{array}{l}2.91(1.51- \\
5.62)\end{array}$ & $0.001 *$ \\
\hline \multirow[t]{8}{*}{ Kebele } & Ejersa & 42 & $29(69.05)$ & 1 & 1 & - & - \\
\hline & Hora & 28 & $21(75.00)$ & $\begin{array}{l}1.34(0.46- \\
3.95)\end{array}$ & 0.590 & - & - \\
\hline & Yahi Geda & 41 & $31(75.61)$ & $\begin{array}{l}1.39(0.53- \\
3.66)\end{array}$ & 0.505 & - & - \\
\hline & $\begin{array}{l}\text { Hora } \\
\text { Ayetu }\end{array}$ & 72 & $55(76.39)$ & $\begin{array}{l}1.45(0.62- \\
3.39)\end{array}$ & 0.392 & - & - \\
\hline & $\begin{array}{l}\text { Burka } \\
\text { Gudina }\end{array}$ & 15 & 14(93.33) & $\begin{array}{l}6.27(0.74- \\
52.90)\end{array}$ & 0.091 & - & - \\
\hline & Gora & 79 & 74(93.67) & $\begin{array}{l}6.63(2.17- \\
20.27)\end{array}$ & $0.001^{*}$ & - & - \\
\hline & Goba & 68 & $64(94.12)$ & $\begin{array}{l}7.17(2.15- \\
23.90)\end{array}$ & $0.001 *$ & - & - \\
\hline & Ayetu & 23 & $22(95.65)$ & $\begin{array}{l}9.86(1.2- \\
81.19)\end{array}$ & $0.033^{*}$ & - & - \\
\hline \multirow[t]{2}{*}{ Sex } & Female & 58 & $46(79.31)$ & 1 & 1 & - & - \\
\hline & Male & 310 & 264(85.16) & $\begin{array}{l}1.46(0.72- \\
2.96)\end{array}$ & 0.294 & - & - \\
\hline \multirow[t]{3}{*}{ Age } & $\begin{array}{l}\text { Juvenile } \\
\text { and ado. }\end{array}$ & 58 & $46(79.31)$ & 1 & 1 & - & - \\
\hline & Adult & 270 & 227(84.07) & $\begin{array}{l}1.38(0.67- \\
2.81)\end{array}$ & 0.380 & - & - \\
\hline & Geriatrics & 40 & $37(92.50)$ & $\begin{array}{l}3.22(0.84- \\
12.25)\end{array}$ & 0.087 & - & - \\
\hline
\end{tabular}

Table 2: Logistic regression analysis results of the association between CLI seropositivity and potential risk factors (cont.). 


\begin{tabular}{|c|c|c|c|c|c|c|c|}
\hline \multirow[t]{2}{*}{ Variable } & \multirow[t]{2}{*}{ Category } & \multirow{2}{*}{$\begin{array}{l}\text { No. } \\
\text { tested }\end{array}$} & \multirow{2}{*}{$\begin{array}{l}\text { No. Pos. } \\
\text { (\%) }\end{array}$} & \multicolumn{2}{|l|}{ Univariable } & \multicolumn{2}{|c|}{ Multivariable } \\
\hline & & & & $\begin{array}{l}\text { COR }(95 \% \\
\mathrm{Cl})\end{array}$ & $\begin{array}{l}\mathrm{P}- \\
\text { value }\end{array}$ & $\begin{array}{l}\mathrm{AOR}(95 \% \\
\mathrm{Cl})\end{array}$ & $\begin{array}{l}\mathrm{P}- \\
\text { value }\end{array}$ \\
\hline \multirow[t]{2}{*}{ Breed } & $\begin{array}{l}\text { Exotic and } \\
\text { cross }\end{array}$ & 64 & $49(76.56)$ & 1 & 1 & 1 & 1 \\
\hline & Local & 304 & $261(85.86)$ & $\begin{array}{l}1.86(0.96- \\
3.6)\end{array}$ & 0.067 & $\begin{array}{l}1.02(0.5- \\
2.11)\end{array}$ & 0.950 \\
\hline \multirow{3}{*}{$\begin{array}{l}\text { Living } \\
\text { environment }\end{array}$} & Indoor & 73 & $53(72.60)$ & 1 & 1 & 1 & 1 \\
\hline & Outdoor & 60 & $51(85)$ & $\begin{array}{l}2.14(0.89- \\
5.13)\end{array}$ & 0.089 & $\begin{array}{l}1.85(0.75- \\
4.57)\end{array}$ & 0.182 \\
\hline & Mixed & 235 & $257(87.12)$ & $\begin{array}{l}2.68(1.41- \\
5.11)\end{array}$ & $0.003^{*}$ & $\begin{array}{l}2.19(1.11- \\
4.33)\end{array}$ & $0.025^{\star}$ \\
\hline \multirow{2}{*}{$\begin{array}{l}\text { Presence of } \\
\text { other animals }\end{array}$} & No & 132 & 109(82.58) & 1 & 1 & - & - \\
\hline & Yes & 236 & 201(85.17) & $\begin{array}{l}1.21(0.68- \\
2.15)\end{array}$ & 0.513 & - & - \\
\hline
\end{tabular}

No. $=$ Number, Pos. $=$ Positive, $\mathrm{COR}=$ Crude Odd Ratio, $\mathrm{AOR}=$ Adjusted Odd Ratio, Juvenile and ado. $=$ Juvenile and adolescent

\section{Figures}




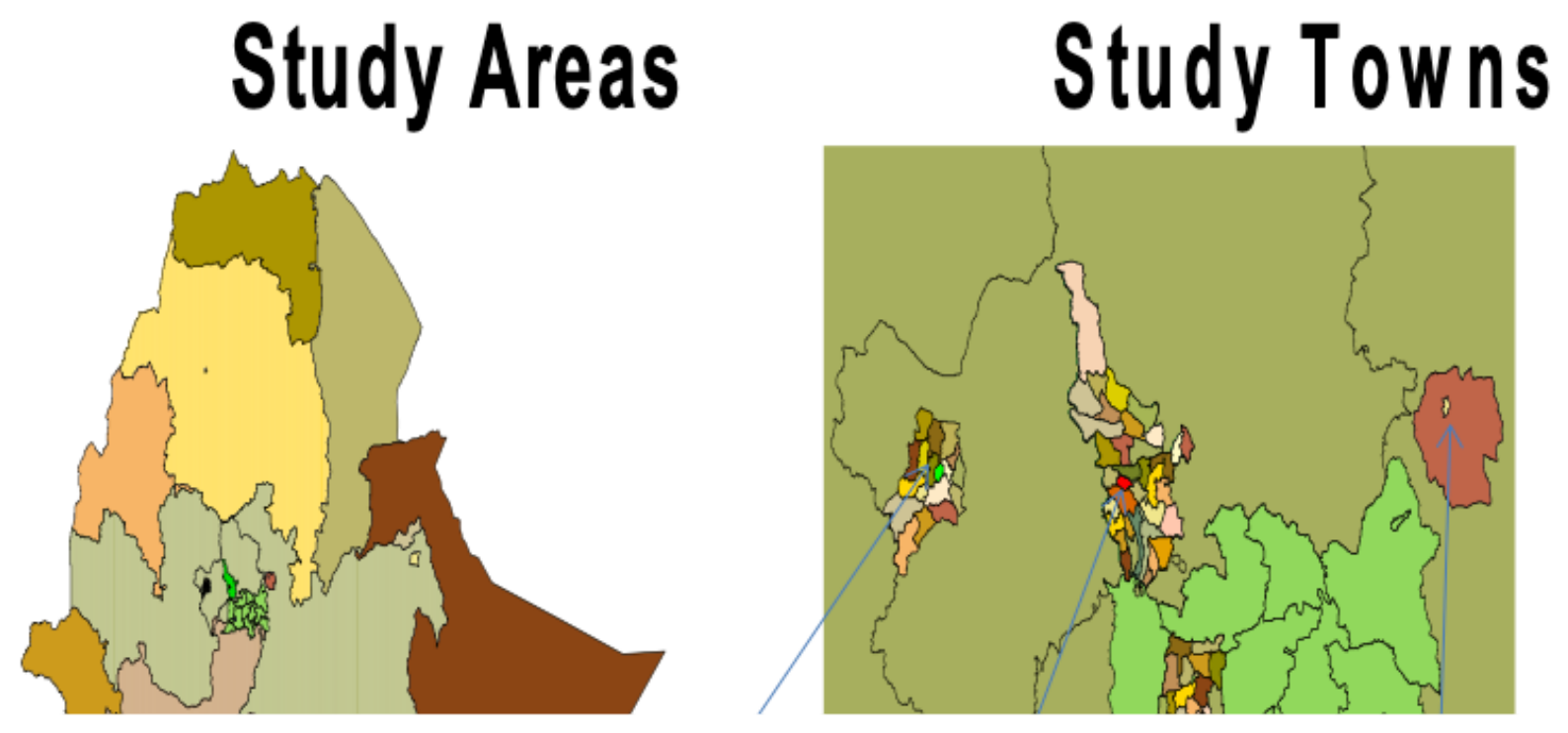

Figure 1

Maps showing the study areas (West Shewa Zone and Elu Gelan District Land Administration and Use Office, 2003). 